\title{
Leucine transport across plasmamembranes from the scud Echinogammarus stammeri (Amphipoda: Gammaridae)
}

\author{
E. Berra, M. Forcella, R. Giacchini, P. Parenti* \\ Department of Environmental Sciences, University of Milano-Bicocca, Piazza della Scienza 1 - 20126 Milano, Italy
}

\begin{abstract}
The freshwater scud Echinogammarus stammeri is a very abundant benthic crustacean in riverine systems of northern Italy. The molecular physiology of L- $\left[{ }^{3} \mathrm{H}\right]$ leucine transport across cell membranes of E. stammeri was investigated. At $\mathrm{pH} 7.4$, the presence of a $\mathrm{NaCl}$ gradient stimulated the leucine transport rate, when compared with $\mathrm{KCl}$ gradient. By contrast, alkaline $\mathrm{pH}$ strongly inhibited transport activity. In $\mathrm{NaCl}$ medium at acidic $\mathrm{pH}$, leucine uptake displayed a specific activity 2.1 -fold lower than that measured at neutral $\mathrm{pH}$. Analysis of the uptake as a function of external leucine concentration revealed saturation kinetics. Leucine uptake appeared broadly unspecific and it was much strongly inhibited by the non-polar amino acids phenylalanine, methionine, and $\mathrm{BCH}$, as well as by hydrophobic hydroxyacids. These results revealed important differences with respect to amino acid transport systems described in marine crustaceans. Their relevance in the feeding adaptation of the scud is briefly discussed.
\end{abstract}

Keywords : amino acid transport, brush border membrane vesicles, Echinogammarus stammeri, Gammaridae

\section{Introduction}

The crustacean digestive system consists of three main divisions: foregut, midgut, and hindgut. Early studies with radioactively labeled substances have demonstrated their specific role in overall nutrient absorption (Speck \& Urich 1970). During the last two decades several studies have been performed on the crustacean gastrointestinal tract to examine the properties of nutrients transport and the physiology of the absorption of sugar, amino acids, and inorganic ions (Ahearn 1974, 1982, 1987). The hepatopancreas, a large multilobate diverticulum of the midgut with a single layer epithelium, has been proved to be responsible for the bulk of nutrient absorption in crustaceans (van Weel 1955, Wright \& Ahearn 1997). Application of membrane vesicle technique to lobster hepatopancreas has resulted in purified brush border membrane fractions able to reproduce transport activities of sugars and amino acids (Ahearn et al 1985, 1986, Ahearn \&

\footnotetext{
* Corresponding author :

E-mail: paolo.parenti@unimib.it
}

Clay 1988). These investigations, while confirming previous studies on perfused intestinal preparations (Maginnis 1977), added new data on the molecular physiology of transport mechanisms in crustaceans. In particular, they revealed the presence of several $\mathrm{Na}^{+}$ dependent and $\mathrm{Na}^{+}$-independent amino acids transport processes, which may or may not include chlorine ions as cosubstrates and all are strongly stimulated by acidic pH (Ahearn 1987). Thus, a model for nutrient transport, which differs from the vertebrate model has been proposed: the acidic luminal $\mathrm{pH}$ of crustaceans substantially modifies substrate charge resulting in substrate specificities which are considerably different between crustaceans and vertebrates. This model was mainly based on studies performed on the Atlantic lobster Homarus americanus and few additional decapod species (Wright \& Ahearn 1997). No information is currently available from other crustacean taxa.

Amphipods are epibenthic peracarid crustaceans widespread on earth and very common in marine, brackish and fresh waters, and in a wide range of groundwater environments. In freshwaters they represent an important source of food for larger species, mostly fishes, and include several species that are able to tolerate or-

Article available at http://www.limnology-journal.org or http://dx.doi.org/10.1051/limn/2006012 
ganic contaminants, so that gammarids have been considered for development of specific biochemical biomarkers (McLoughlin et al. 2000). The gammarid Echinogammarus stammeri (Karaman 1931) is widely distributed in the Alpine region of northern Italy, slightly extending into the Apennine peninsula and crossing the border into France, Switzerland, and Slovenia. As most other scuds this species up benthic habits, it feeds on coarse particulate material of different origin and, consequently has an important role in detritus processing and nutrient cycling in freshwater ecosystems (Karaman 1993). While data about nutrient absorption in other macrobenthic invertebrates are available (Parenti et al. 2001, Forcella et al. 2004), nothing is known on freshwater crustaceans. Cell membranes purified in form of closed vesicles are a useful tool in the characterization of molecular features of transport systems (Lucke et al. 1978, Ahearn, 1987, Parenti et al. 2000). However, species of relatively small size, such as E. stammeri, have been excluded from these studies. Therefore, in order to add new data on comparative physiology of nutrient absorption in freshwater Crustacea, an investigation on the properties of leucine transport across purified plasmamembranes from E. stammeri was undertaken.

\section{Material and methods}

\section{Animals}

Specimens of E. stammeri (length $>5 \mathrm{~mm}$ ) were collected at several localities along the Ticino River, northern Italy, maintained in large vessels at $6 \pm 1{ }^{\circ} \mathrm{C}$, and fed ad libitum with Tetramin ${ }^{\circledR}$ for 1-2 weeks before use for experiments.

\section{Chemicals}

$\mathrm{L}-\left[4,5-{ }^{3} \mathrm{H}\right]$-leucine $152 \mathrm{Ci} / \mathrm{mmol}$ was purchased from Amersham Pharmacia Biotech. Leucine, HEPES (4-(2-hydroxyethyl)piperazine-1-propansulfonic acid), Tris (2-amino-2-(hydroxymethyl)-1,3-propanediol), enzyme, substrates, and coenzymes were from Sigma-Aldrich.

\section{Brush border membrane preparation}

Membrane vesicles were prepared using the method described by Wolfersberger et al. (1987) with minor modifications. Briefly, animals (roughly 3 g per experiment) were suspended with 9 volumes of a hypotonic Tris buffer (Tris-HCl 17 mM, pH 7.4, mannitol 100 $\mathrm{mM}$, EGTA $5 \mathrm{mM}$ ) and homogenized at $4^{\circ} \mathrm{C}$ in a glass and teflon Potter-Helvehjem, two 9-strokes at 3,000 rpm, separated by 2 min in ice. The suspension was then filtered through two layers of surgical gauze. An equal volume of $24 \mathrm{mM} \mathrm{MgCl}_{2}$ was added to the recovered volume. The resulting mixture was thoroughly stirred for $15 \mathrm{~min}$ in an ice bath and then centrifuged at $2,500 \mathrm{~g}$ for $15 \mathrm{~min}$ at $4^{\circ} \mathrm{C}$. The resulting pellet was discarded and the supernatant centrifuged at 48,000 $\mathrm{g}$ for $20 \mathrm{~min}$ at $4^{\circ} \mathrm{C}$. The pellet was resuspended in 0.5 homogenate volume of cold Tris buffer and homogenized in a glass and teflon Potter-Helvehjem, two 6-strokes at 2,000 rpm, separated by $1 \mathrm{~min}$ in ice. After addition of an equal volume of $24 \mathrm{mM} \mathrm{MgCl}$, the mixture was stirred for $15 \mathrm{~min}$ in an ice bath and centrifuged as above at low speed and then at high speed. The final pellet was resuspended in 1 vol of initial buffer, homogenized in Potter-Helvehjem as before, and centrifuged again at 48,000 $\mathrm{g}$ for $20 \mathrm{~min}$ at $4^{\circ} \mathrm{C}$. The obtained pellet was resuspended in HEPES-Tris $10 \mathrm{mM}, \mathrm{pH} 7.4$, mannitol $100 \mathrm{mM}$, and represented the membrane preparation used for transport experiments. The recovery was about $0.8 \mathrm{mg}$ membrane proteins/g fresh individuals. For transport experiment, the suspension was made at a protein concentration of $2-3 \mathrm{mg} / \mathrm{ml}$ as assayed according to Bradford (1976) using bovine serum albumin as standard.

\section{Transport experiments}

Amino acid uptake studies were performed at $22^{\circ} \mathrm{C}$ by incubating $10 \mu \mathrm{l}$ of freshly prepared vesicles and $40 \mu \mathrm{l}$ of an appropriate radioactive cocktail, including $\mathrm{L}-^{3}[\mathrm{H}]$-Leucine $(30-90 \mu \mathrm{Ci} / \mathrm{ml})$, as reported in the figure legends. Uptake studies were performed by a rapid filtration technique described elsewhere (Parenti et al. 1992). Incubation was stopped by the addition of 50 volumes of ice-cold stop solution $(150 \mathrm{mM} \mathrm{NaCl}, 10$ mM HEPES-Tris, $\mathrm{pH}$ 7.2) and the overall solution was filtered under vacuum through pre-wetted mixed-esters cellulose filter $(0.45 \mu \mathrm{m}$ pore size, Micro Filtration System, Dublin, California). Filters were quickly rinsed with $10 \mathrm{ml}$ of ice-cold stop solution and filter-associated radioactivity was counted in a scintillation spectrometer Tri-Carb, Packard, model 300 C. Each experiment was performed in triplicate and repeated at least three times with different membrane preparations. Uptakes were expressed as nmol/mg of membrane proteins. Experimental data are given with \pm SE and analyzed by computer using a multiparameter, iterative, non-linear regression program based on the Marquardt-Levenberg algorithm (Sigma Plot, Jandel, CA).

\section{pH measurements in vivo}

To estimate the lumen $\mathrm{pH}$ (Zhuang et al. 1999), individual gammarids were dissected alive on a microsco- 
pic slide, the intestine was isolated and examined under a Leica stereomicroscope adding one of the following indicators (in powder to not dilute body fluids): phenolphthalein, thymol blue and cresol red. Segments were compared visually with standards prepared in step of approximately $0.5 \mathrm{pH}$ units.

\section{Results}

Purity of membrane preparation from whole $E$. stammeri prepared by magnesium precipitation was assessed by comparing the activity of the membranebound enzyme leucine aminopeptidase (LAP) in whole homogenate and in final membrane suspension. LAP specific activity was enriched significantly over the specific activity in the whole animal homogenate. The values were $0.6 \pm 0.1 \mathrm{mU} / \mathrm{mg}$ and $6.2 \pm 0.2$ $\mathrm{mU} / \mathrm{mg}$ in crude extract and in membrane preparation, respectively. In contrast cytochrome c oxidase did not exhibit increased activity in the enriched membrane fraction. This result indicates that the preparation was mainly represented by brush border membranes of gut origin. The yield was $0.34 \pm 0.04 \mathrm{mg}$ of membrane proteins per gram of wet weight.

The incubation of the membrane preparation from $E$. stammeri in a medium containing tracer amount of labeled substrates demonstrated that these membranes are constituted by closed vesicles able to take up the labeled compounds as it has been demonstrated by similar preparations made from mammalian intestine (Lucke et al. 1978), crustacean hepatopacreas (Ahearn et al. 1986) or insect midgut (Parenti et al. 1992). The presence of closed vesicles is believed whenever a so-called "overshoot" phenomenon is observed, i.e. a transient accumulation of labeled compound at short time $(15-60 \mathrm{sec})$ of incubation greater than that observed after a prolonged time (60-120 $\mathrm{min})$ of incubation. In preliminary experiments performed in E. stammeri vesicles, such an overshoot phenomenon was observed in the presence of labeled amino acid, whereas it was not detected using D-[ $\left.{ }^{14} \mathrm{C}\right]$ glucose irrespective of the composition of the incubation buffer (not shown). Maximal effects were observed with $\mathrm{L}-\left[{ }^{3} \mathrm{H}\right]$ leucine as tracer and for this reason we decided to further characterize the transport system in these crustaceans.

Figure 1 shows the time-course of $0.05 \mathrm{mM}$ leucine uptake in the presence of an inwardly directed $\mathrm{NaCl}$ or $\mathrm{KCl}$ gradient $\left(100 \mathrm{mM}_{\text {out }} / \sim 0 \mathrm{mM}_{\text {in }}\right)$ at slightly alkaline $\mathrm{pH}$. After one minute of incubation, in the presence of sodium, but not potassium, the intravescicular amino acid concentration was 6.7 higher than that measured at the equilibrium, which suggests the presence of a highly efficient sodium-dependent carrier-mediated amino acid transport system.

To ascertain whether leucine transport exhibited a requirement for chloride, as demonstrated in other crustaceans, or for more alkaline medium $\mathrm{pH}$ a second set of measurements were performed (Fig. 2). Results indicated that in the presence of $\mathrm{NaCl}$ the uptake rate is 2-fold higher than that measured in the absence of salts (Fig. 2, column $b$ vs $a$ ) or 1.85 -fold higher than that measured in the presence of $\mathrm{KCl}$ (Fig. 2, column $b$ vs $c)$. In the presence of sodium ions, the rate increased, albeit slightly, when $\mathrm{Cl}^{-}$was substituted by the more lipophilic anion thiocyanate $\left(\mathrm{SCN}^{-}\right)$, suggesting that uptake was in some way sensitive to changes of membrane potential (Fig. 2, column $b$ vs $d$ ). This effect was not observed in the presence of potassium ions. A similar pattern of cation and anion specificity was obtained when medium $\mathrm{pH}$ was shifted at value 8.4 , even though, in all conditions, uptake rate were significantly lower than the corresponding rates measured at $\mathrm{pH}$ 7.4.

Next, the effect of acidic medium $\mathrm{pH}$ on leucine uptake was investigated. When extravesicular $\mathrm{pH}$ was reduced from 7.4 to 5.0 a decrease of the specific activity of the sodium-dependent leucine uptake was observed, whereas the cation-independent component, measured in the presence of potassium or in the absence of added salts remained unchanged (Fig. 3). In vivo measurements of lumen $\mathrm{pH}$ in single individuals emphasized a slightly alkaline $\mathrm{pH}$ in the midgut. When cresol red + thymol blue became in contact with the inner content of the midgut the yellow color suddenly changed to a deep violet if the midgut content has a $\mathrm{pH}$ close to 8.0. The color change was not much evident in $E$. stammeri, which showed a light blue coloration. Accordingly, phenolphthalein failed to change color, indicating that the lumen $\mathrm{pH}$ value was well below 10 . These data are in agreement with $\mathrm{pH}$ dependence of leucine uptake as measured above.

Uptake of $0.01 \mathrm{mM} \mathrm{L}-\left[{ }^{3} \mathrm{H}\right]$ leucine was a linear function of time from 3 to 20 seconds of incubation, whereas that for $0.5 \mathrm{mM} \mathrm{L}-\left[{ }^{3} \mathrm{H}\right]$ leucine was linear until 10 seconds of incubations (not shown). Therefore, 7 seconds of incubation was chosen as a good estimation of initial rate for studies of the effect of substrate concentration on leucine uptake. Then, transport measurements were corrected for non-specific binding by subtraction a blank uptake made by adding simultaneously the radioactive cocktail and the vesicles suspension to the stop solution. Figure 4 shows the effect of leucine concentration $(0.001$ to $0.5 \mathrm{mM})$ on $\mathrm{L}$ $\left[{ }^{3} \mathrm{H}\right]$ leucine influx from an incubation medium buffered at $\mathrm{pH} 7.4$ and containing $100 \mathrm{mM} \mathrm{NaCl}$. Over the 


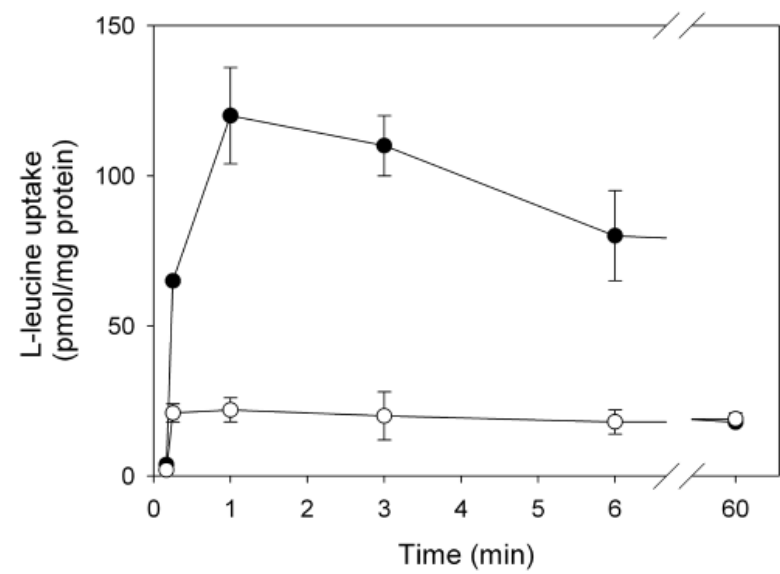

Fig. 1. Time course of leucine uptake into BBMV from E. stammeri. One volume of vesicles prepared in $20 \mathrm{mM}$ HEPES-Tris, $\mathrm{pH}$ 7.4 and $100 \mathrm{mM}$ mannitol were diluted into four volumes of the same buffer, containing $100 \mathrm{mM} \mathrm{NaCl}$ (closed symbols) or 100 $\mathrm{mM} \mathrm{KCl}$ (open symbols). Incubation buffers included $0.01 \mathrm{mM}$ ${ }^{3} \mathrm{H}$-leucine. At the indicated times, mixture was blocked by dilution in ice-cold stop solution as described in Material and Methods. Data represents mean \pm S.E. of four determinations.

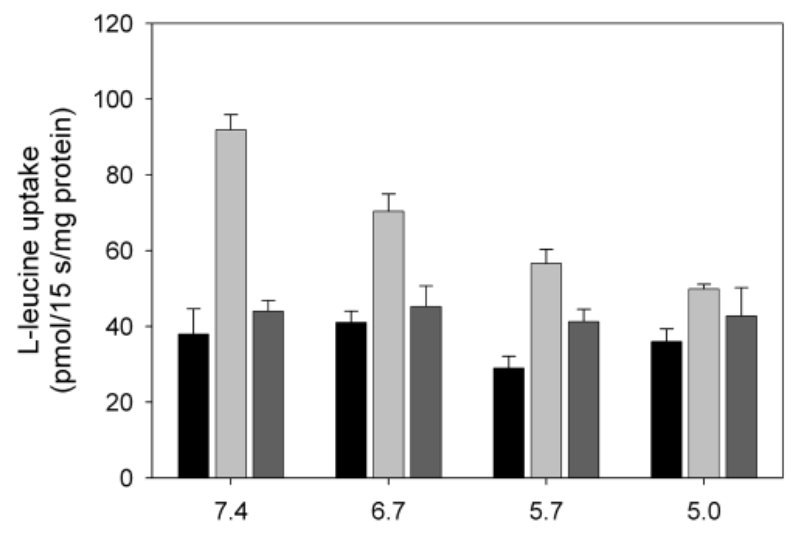

Fig. 3. Effect of acidic $\mathrm{pH}$ on leucine uptake into BBMV from $E$. stammeri. Vesicles prepared as in Fig. 1 were diluted in the same buffer (pH 7.4) and in $100 \mathrm{mM}$ MES-Tris solutions buffered at $\mathrm{pH} 6.5,5.5$ and 4.0 to give the indicated final $\mathrm{pH}$ values. Uptake was performed in the presence of $100 \mathrm{mM}$ mannitol (black bar), $100 \mathrm{mM} \mathrm{NaCl}$ (light gray bar) or $100 \mathrm{mM} \mathrm{KCl}$ (gray bar) and $0.01 \mathrm{mM}{ }^{3} \mathrm{H}$-leucine. Data represents mean \pm S.E. of four determinations.

above amino acid concentration range, uptake was a curvilinear function of external leucine concentration and could be described by the sum of at least two independent processes acting simultaneously: i) a carriermediated process displaying saturation kinetics and

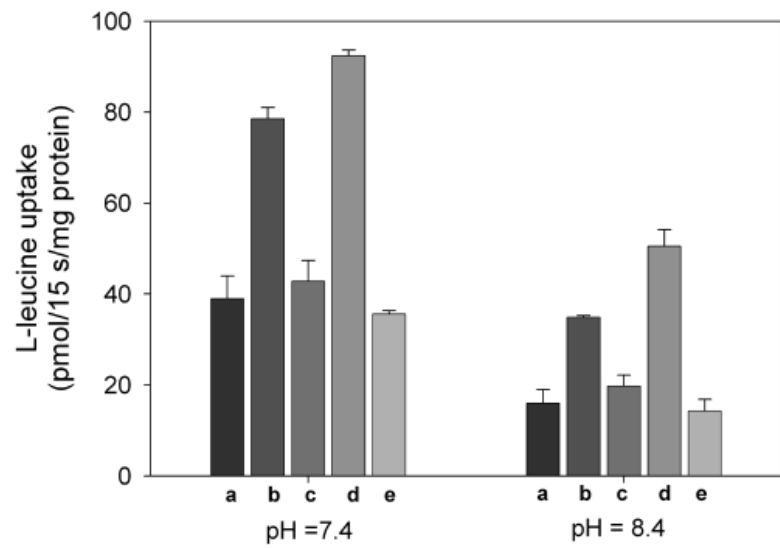

Fig. 2. Effect of alkaline pH on leucine uptake into BBMV from $E$. stammeri. Vesicles prepared as in Fig. 1 were diluted in the same buffer ( $\mathrm{pH} 7.4$ ) and in $20 \mathrm{mM}$ Tris- $\mathrm{HCl} \mathrm{pH} 10.8$ (final $\mathrm{pH} 8.4$ ), containing $100 \mathrm{mM}$ mannitol (a), $100 \mathrm{mM} \mathrm{NaCl}$ (b), $100 \mathrm{mM}$ $\mathrm{KCl}$ (c), $100 \mathrm{mM} \mathrm{NaSCN}$ (d) or $100 \mathrm{mM} \mathrm{KSCN} \mathrm{(e)} \mathrm{and} 0.01 \mathrm{mM}$ ${ }^{3} \mathrm{H}$-leucine. Data represents mean \pm S.E. of four determinations.

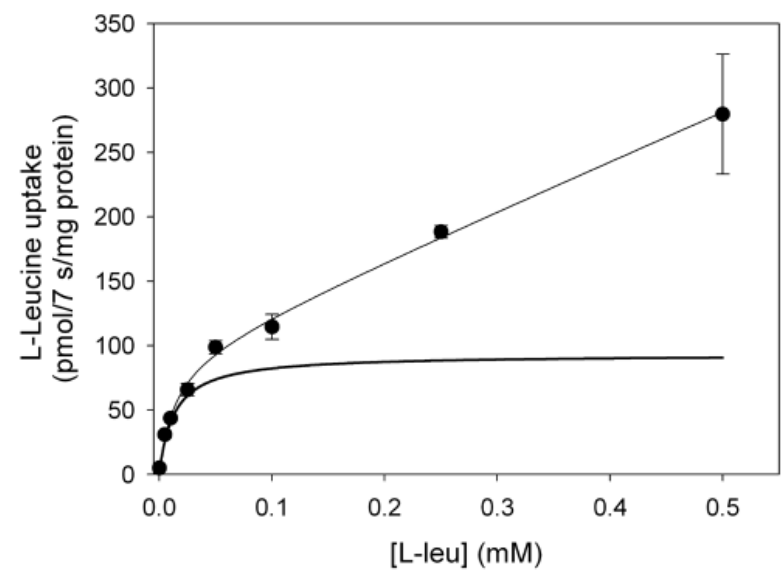

Fig. 4. Leucine uptake as a function of leucine concentration. Initial rates of leucine uptake were measured in the presence of $100 \mathrm{mM}$ $\mathrm{NaCl}$, at $\mathrm{pH} \mathrm{7.4,} \mathrm{and} \mathrm{at} \mathrm{the} \mathrm{indicated} \mathrm{leucine} \mathrm{concentrations.} \mathrm{Ove-}$ rall uptake was corrected for non saturable component to give hyperbolic component representing the carrier-mediated process (see text for details).

described by the Michaelis-Menten equation, and ii) a linear entry system proportional to external leucine concentration representing a low affinity transport system or simple diffusion. Therefore the overall process is described by the following equation: 


$$
v_{0}=\frac{V_{\max } \cdot[\mathrm{Leu}]}{K_{\text {Leu }}+[\mathrm{Leu}]}+C \cdot[\mathrm{Leu}]
$$

where $\mathrm{v}_{0}$ is the initial rate of leucine uptake; $V_{\max }$, the maximal initial uptake rate; $K_{L e u}$ is the affinity constant also called Michaelis-Menten constant for leucine; and $\mathrm{C}$ is a constant accounting for the linear component, often referred as "diffusional component". The kinetic parameters estimated from two independent experiments are reported in Table 1. The data indicated that the carrier-mediated sodium-dependent leucine uptake has a strong affinity for its substrate, the leucine, as the affinity is in the micromolar range, and, therefore, saturate at concentration of about $0.2 \mathrm{mM}$ leucine. As a matter of fact at this leucine concentration the ratio $\mathrm{V}_{\max } \cdot[\mathrm{Leu}] /\left(K_{\text {Leu }}+[\mathrm{Leu}]\right)$ in equation (1) is close to $V_{\max }$, the maximal velocity. More elevated concentrations could be taken up through less specific transport systems which saturated at high substrate concentration and that in the range of concentration used here are indistinguishable from simple diffusion. Saturation was present only in the presence of sodium e we were unable to demonstrate saturation kinetics in the same range of leucine concentration used above when sodium was substituted by potassium.

Table 1. Kinetics of leucine uptake into BBMV from E. stammeri. Kinetics parameters were calculated by fitting the experimental data illustrated in Figure 3 and in an additional experiment to the equation (1) reported in the text. Estimation was made using a non-linear regression program as cited in Materials and Methods.

\begin{tabular}{lcc}
\hline Parameter & 1st experiment & 2nd experiment \\
\hline$K_{\text {Leu }}$ & $0.013 \pm 0.003$ & $0.014 \pm 0.006$ \\
$\mathrm{~V}_{\max }(\mathrm{pmol} / 7 \mathrm{~s} / \mathrm{mg}$ protein) & $93.1 \pm 7.5$ & $95.5 \pm 10.9$ \\
Diffusional component $\left(\mathrm{min}^{-1}\right)$ & $381 \pm 19$ & $270 \pm 55$ \\
\hline
\end{tabular}

Previous vesicles study (Parenti et al. 2000) suggested that leucine uptake can be competitively inhibited by a number of amino acids and analogues. To assay specificity of leucine transport into membrane vesicles from E. stammeri, $0.01 \mathrm{mM} \mathrm{L}-\left[{ }^{3} \mathrm{H}\right]$ leucine uptake was measured in the presence of a 20 -fold excess of unlabeled amino acids, analogues, and derivatives. Initial uptake rate measurements in the presence of $100 \mathrm{mM}$ $\mathrm{NaCl}$ at $\mathrm{pH} 7.4$ were performed. Results are shown in Table 2. Almost all the compounds tested as inhibitors produced a reduction of the specific leucine uptake as determined against a control in the presence of mannitol. From the calculated residual activity $(i)$ and assu-
Table 2. Inhibition of leucine uptake in BBMV from E. stammeri.

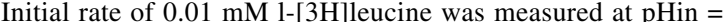
$\mathrm{pHout}=7.4,100 \mathrm{mM} \mathrm{NaCl}$, and in the presence of $0.2 \mathrm{mM}$ of the indicated inhibitor. Residual activity was calculated from a control in the presence of mannitol. The inhibition constant $\mathrm{Ki}$ was determined assuming competitive inhibition.

\begin{tabular}{lll}
\hline Inhibitor & residual activity $(\%)$ & $\mathrm{K}_{\mathrm{i}}(\mathrm{mM})$ \\
\hline L-Leucine & 10.1 & 0.015 \\
L-Phenylalanine & 17.0 & 0.023 \\
L-Methionine & 23.4 & 0.034 \\
L-Alanine & 40.5 & 0.076 \\
L-Proline & 60.3 & 0.172 \\
Glycine & 51.1 & 0.118 \\
L-Lysine & 63.7 & 0.198 \\
L-Glutamic acid & 87.7 & 0.518 \\
B-Alanine & 60.0 & 0.170 \\
BCH & 57.4 & 0.152 \\
Acivicin & 32.6 & 0.055 \\
L-Leucine methyl ester & 57.1 & 0.150 \\
L-Leucine ethyl ester & 52.4 & 0.125 \\
Glycine methyl ester & 88.0 & 0.530 \\
2-hydroxyvaleric ethyl ester & 56.3 & 0.146 \\
3-hydroxybenzoic methyl ester & 46.9 & 0.100 \\
4-hydroxybenzoic methyl ester & 45.8 & 0.095 \\
\hline
\end{tabular}

ming pure competitive inhibition, the $\mathrm{mM}$ inhibition constant $\left(K_{i}\right)$ can be estimated according to the following equation:

$$
i=\frac{[I]}{[I]+K_{i}\left(1+\frac{[S]}{K_{\text {Leu }}}\right)}
$$

In principle, uncompetitive inhibition could be expected if the inhibitor, by using the same sodium gradient, decrease sodium availability for the transport to be measured. The low concentration $(0.2 \mathrm{mM})$ of the inhibitor and the short time $(7 \mathrm{~s})$ selected for uptake determination, ruled out this possibility. As shown in Table 2, leucine uptake was strongly inhibited by hydrophobic amino acids (phenylalanine, methionine, and alanine) and bulky hydrophobic analogues $(\mathrm{BCH}$, acivicin). The transport was also inhibited by hydrophobic amino esters and hydroxyacids, suggesting that the side chain of the amino acid play a major role in the binding to the transport protein. Glycine was a quite good inhibitor, but not its derivative glycine methyl ester, indicating that, as expected, the $\alpha$-carboxylic 
group is important for binding to the carrier protein. Also, a contribution is given by the amino group: $\beta$ alanine is a poor inhibitor compared to common alanine. However, $\alpha$-hydroxyesters are able to significantly inhibit leucine uptake, demonstrating the importance of the presence of a hydrophilic group on the a-carbon of the substrate molecule. Recently (Leonardi et al., 2001), a potent activation mechanism by leucine methyl ester and few related compounds has been described in Insects. As shown in Table 2, these substances produced inhibition rather than activation of leucine uptake in E. stammeri.

\section{Discussion}

MacIntosh et al. (1994) reported for the first time an experimental procedure aimed to obtain purified brush border membranes from whole invertebrates of tiny size. This methodology combined the well-known $\mathrm{Mg}^{++}$ precipitation-differential centrifugation protocol (Wolfersberger et al. 1987) with low speed centrifugation and filtration on cheesecloth. Since then it has been used both for binding studies (Abdul-Rauf \& Ellar 1999) and transport experiments (Parenti et al. 2001). In this paper, we present results on solute transport capability in a membrane preparation obtained from whole animals of the freshwater crustacean species $E$. stammeri. This preparation was apparently composed of closed vesicles able to take up amino acids, as evidenced by the radiolabeled tracer $\mathrm{L}-\left[{ }^{3} \mathrm{H}\right]$ leucine. Uptake was sodium-dependent, chloride-insensitive and $\mathrm{pH}$-dependent, with an optimum at slightly alkaline values around $\mathrm{pH}$ 7.4. In addition, leucine transport was mediated by a specific carrier protein, which saturated at about $0.2 \mathrm{mM}$ leucine and can use, as substrates, additional amino acids, mainly hydrophobic. If external leucine concentration was further increased, the relationship between the uptake rate and the concentration followed a quasi-linear pattern, suggesting that other mechanisms, probably diffusional or low affinity systems, could be involved in amino acid absorption.

Most of what we know about molecular physiology of nutrient transport processes in the crustacean gastrointestinal tract came from studies on hepatopancreas brush border membrane vesicles from the lobster Homarus americanus (Wright \& Ahearn 1997). These studies were a consequence of a series of physiological data demonstrating a minimal role of the crustacean intestine in total nutrient transport (Ahearn 1982). Vesicles obtained from lobster hepatopancreas using the magnesium precipitation method were employed to characterize several organic solute transporters, inclu- ding D-glucose, a number of L-amino acids and inositol. A summary of the findings of these studies indicated the presence of at least seven transport systems, of which four are sodium-dependent and three are sodium-independent. The former include the carrier systems for D-glucose, inositol, L-leucine, and L-glutamate, the latter group contains the transporter for L-alanine (able to recognize also L-lysine and L-arginine), Lproline, and a second system for L-leucine. In the case of L-glutamate and L-leucine sodium-dependent systems, a stimulatory effect of chloride ions was observed. Moreover, a reduction of $\mathrm{pH}$ down to $4.0 \mathrm{had}$ a marked stimulatory effect on uptake rate of both $\mathrm{Na}^{+}-$ dependent and $\mathrm{Na}^{+}$-independent transport systems.

The main result reported in the present paper is that, despite differences in ionic concentrations between marine and freshwater habitat, Echinogammarus appears to use a strategy to move organic molecules into its cells similar to that present in Homarus. Important differences are, however, present. Variations between amino acid uptake from the scud E. stammeri and that reported in the lobster $H$. americanus, can be related to the ecological niche occupied by the two species and their feeding behaviour. A number of variations are quantitative in nature, such as the very high affinity found in Echinogammarus (the $K_{\mathrm{m}}$ for leucine is one order of magnitude lower in the scud compared to that measured in the lobster). However, some differences are qualitative, such as the decrease of the specific transport activity at the acidic $\mathrm{pH}$ observed in Echinogammarus compared to data obtained in Homarus. The sensitivity to medium $\mathrm{pH}$ appears the main feature, which distinguishes Echinogammarus from Homarus. Gastric content of Homarus is acidic and is periodically flushed through hepatopancreas tubules, where they come into contact with apical surfaces of absorptive cells (Wright \& Ahearn 1997). Thus protons can be used as driving force to further increase nutrient transport rate and absorption efficiency. Homarus is primarily carnivorous and there are evidences that when proteins are the primary food material the lumen $\mathrm{pH}$ tends to be slightly acidic (O'Riordan 1969). The ultrastructure of hepatopancreatic caeca has been examined in Gammarus minus (Schultz 1976) and the author concluded that within the Malacostraca the hepatopancreatic epithelium of Amphipoda is more similar to that of Decapoda than that of Isopoda. Despite these structural similarities, our results show that Echinogammarus does not use protons as driving force for amino acid uptake. The trophic ecology of gammarids has been recently revisited by MacNeil et al. (1997). They concluded that, although gammarids are typical- 
ly viewed as archetypal shredders and their herbivorous nature has been emphasized in several studies, this trophic classification must be treated with caution when applied to this group of macroinvertebrates. Gammarids are potentially omnivorous, able to utilize a wide range of food resources, and showing high herbivore/predator plasticity switching between foods as they became available. This feature seems compatible with the presence of basal sodium-dependent transport systems for organic solutes. Therefore, for amino acid uptake, Echinogammarus did not evolve specializations, such as the use of protons, as in Homarus, or potassium ions, as in phytophagous insects (Giordana et al. 1998). This absence of specialization may contribute to the ability to assimilate a diverse suite of foods, which in turn could contribute to the capability of the gammarids to persist in and colonize new habitats, and to live in disturbance-prone aquatic ecosystems such as rivers where food resources may be highly transitory. The effect of changing environment on membrane transport of organic solute in freshwater invertebrates is completely unrecorded and E. stammeri could represent a good model to investigate these aspects.

\section{Acknowledgement}

This work was supported by grant from the University of MilanoBicocca (F.A.R. project 2003).

\section{References}

Abduf-Rauf M. \& Ellar D.J. 1999. - Isolation and characterization of brush border membrane vesicles from whole Aedes aegypti larvae. J. Invert. Pathol., 73, 45-51.

Ahearn G.A. 1974. - Kinetic characteristics of glycine transport by the isolated midgut of the marine shrimp, Penaeus marginatus. J. Exp. Biol., 61, 677-696.

Ahearn G.A. 1982. - Water and solute transport by crustacean gastrointestinal tract. Pages 261-339 in Podesta R.B. (Ed.) Membrane Physiology of Invertebrates, Marcel-Dekker, New York.

Ahearn G.A. 1987. - Nutrient transport by the crustacean gastrointestinal tract: recent advances with vesicles studies. Biol. Rev., 62, 45-63.

Ahearn G.A. \& Clay L.P. 1988. - Sodium-coupled sugar and amino acid transport in an acidic microenvironment. Comp. Biochem. Physiol. A, 90, 627-634.

Ahearn G.A., Grover M.E. \& Dunn R.E. 1985. - Glucose transport by lobster hepatopancreatic brush-border membrane vesicles. Am J Physiol., 248, R133-R141.

Ahearn G.A., Grover M.E. \& Dunn R.E. 1986. - Effects of $\mathrm{Na}^{+}, \mathrm{H}^{+}$, and $\mathrm{Cl}^{-}$on alanine transport by lobster hepatopancreatic brush border membrane vesicles. J. Comp. Physiol. B, 156, 537-548.

Bradford M.M. 1976. - A rapid and sensitive method for the quantitation of protein utilizing the principle of dye-protein binding. Anal. Biochem., 72, 248-254.

Forcella M., Berra, E., Giacchini, R., Hanozet G.M. \& Parenti P. 2004. - Changes in leucine transport activity in Chironomus riparius larvae after short-term exposure to potassium dichromate and fenitrothion. Arch. Insect Biochem. Physiol. 55, 90-101.
Giordana, B., Leonardi, M.G., Casartelli, M., Consonni, P. \& Parenti, P. 1998. - $\mathrm{K}^{+} /$neutral amino acid symport of Bombyx mori larval midgut: a system operative in extreme conditions. Am. J. Physiol., 274, R1361-R1371.

Karaman G.S. 1993. - Crustacea Amphipoda (d'acqua dolce). Fauna d'Italia, Edizioni Calderini, Bologna.

Karaman S., 1931. - Beitrag zur Kenntnis der Süsswasser-Amphipoden. Bull. Soc. Scient. Skoplje, 9, 93-107.

Leonardi, MG, Casartelli, M., Fiandra, L., Parenti, P. \& Giordana, B. 2001. - Role of specific activators of intestinal amino acid transport in Bombyx mori larval growth and nutrition. Arch. Insect Biochem. Physiol., 48, 190-198.

Lucke H.W., Berner W., Menge H. \& Murer H. 1978. - Sugar transport by brush border membrane vesicles isolated from human small intestine. Pfluegers Arch., 373, 243-248.

Maginnis L.A. 1977. - Glucose transport by the perfused midgut of the freshwater prawn, Macrobrachium rosenbergii. University of Hawaii Press, Honolulu.

MacIntosh S.C., Lidster B.D. \& Kirkham C.L. 1994. - Isolation of brush border membrane vesicles from whole diamondback moth (Lepidoptera: Plutellidae) larvae. J. Invert. Pathol., 63, 97-98.

MacNeil C., Dick J.T.A. \& Elwood R.W. 1997 - The trophic ecology of freshwater Gammarus spp. (Crustacea: Amphipoda): problems and perspectives concerning the functional feeding group concept. Biol. Rev., 72, 349-364.

McLoughlin N., Yin D., Maltby L., Wood R.M. \& Yu H. 2000. Evaluation of sensitivity and specificity of two crustacean biochemical biomarkers. Environm. Toxicol. Chem., 19, 2085-2092.

O'Riordan A.M. 1969. - Electrolyte movement in the isolated midgut of the cockroach (Periplaneta americana). J. Exp. Bio.l, 51, 699-714.

Parenti P., Forcella M., Pugliese A, Casartelli M., Giordana B. Leonardi M.G. \& Hanozet G.M. 2000. - Substrate specificity of the brush border $\mathrm{K}^{+}$-leucine symport of Bombyx mori larval midgut. Insect Biochem. Mol. Physiol., 30, 243-252.

Parenti P., Forcella M., Pugliese A., Giacchini R., Rossaro B. \& Hanozet G.M. 2001. - Leucine transport in membrane vesicles from Chironomus riparius larvae displays a mélange of crown-group features. Arch. Insect Biochem. Physiol., 48, 51-62.

Parenti P., Villa M., \& Hanozet G.M. 1992. - Kinetics of leucine transport in brush border membrane vesicles from lepidopteran larvae midgut. J. Biol. Chem., 267, 15391-15397.

Schultz T.W. 1976. - The ultrastructure of the hepatopancreatic caeca of Gammarus minus (crustacea, amphipoda). J. Morphol. 149, 383-399.

Speck U. \& Urich K. 1970. Das schicksal der Nahrstoffe bei dem Flussfrebis Orconectes limosus. II. Resorption-U- ${ }^{14}$ C-markeiter Nahrstoffe und ihre Verteilung auf Organe. Z. Vergl. Physiol., 68, 318-333.

Van Weel P.B. 1955. - Processes of secretion, restitution, and resorption in gland of midgut (glanula media intestini) of Atya spinipes Newp. Physiol. Zool., 28, 40-45.

Wolfersberger M.G., Lüthy P., Maurer A., Parenti P., Sacchi F.V., Giordana B., \& Hanozet G.M. 1987. - Preparation and partial characterization of amino acid transporting brush border membrane vesicles from the larval midgut of the cabbage butterfly Pieris brassicae. Comp. Biochem. Physiol., 86A, 301-308.

Wright S.H. \& Ahearn G.A. 1997. - Nutrient absorption in invertebrates. Pages 1137-1205 in Dantzler W.H. (Ed.). Handbook of Physiology, Oxford University Press, Oxford and New York

Zhuang Z.P., Linser P.J. \& Harvey W.R. 1999. - Antibody to H+ VATPase subunit E colocalizes with portasomes in alkaline larval midgut of a freshwater mosquito (Aedes aegypti L.). J. Exp. Biol., 202, 2449-2460. 